\title{
Chloroform infiltrate temperature sensor using asymmetric circular dual-core photonic crystal fiber
}

\author{
Md. Mahbub Hossain ${ }^{1 *}$, Rajib Mandal ${ }^{1}$, Md. Ziaul Amin ${ }^{1,2}$, Himadri Shekhar Mondal ${ }^{1}$, \\ and Md. Ekhlasur Rahaman ${ }^{1}$ \\ ${ }^{1}$ Electronics and Communication Engineering Discipline, Khulna University, Khulna 9208, Bangladesh \\ ${ }^{2}$ MQ Photonics, School of Engineering, Macquarie University, New South Wales 2109, Australia \\ * e-mail: mahbub.eceku@yahoo.com
}

\begin{abstract}
A new temperature sensor based on asymmetry in dual circular core photonic crystal fiber (ADCPCF) is proposed where both the cores infiltrate by chloroform. To analyze the temperature dependent propagation characteristics, the thermo-optic coefficient of chloroform and silica is used. The asymmetry of the dual-core is confirmed by using the core radius of 1.615 and $1.45 \mu \mathrm{m}$, respectively. In the proposed design, the essential optical properties such as effective refractive index difference (birefringence), coupling length, and transmission spectra are determined by employing the finite element method (FEM) with the perfectly matched layer (PML). The effective refractive index of the chloroform varies with temperature within a certain range. Moreover, with the increase of every $1^{\circ} \mathrm{C}$ temperature the effective index difference enhances to almost $4 \%$. Also, with the reduction of every $100 \mathrm{~nm}$ wavelength the birefringence decrease to $0.125 \times 10^{-3}$ and $0.092 \times 10^{-3}$ for 35 and $30^{\circ} \mathrm{C}$ temperature, respectively. The Numeric analysis shows the maximum sensitivity of $49.80 \mathrm{~nm} /{ }^{\circ} \mathrm{C}$ at $1.61 \mathrm{~mm}$ fiber length for $2.9 \mu \mathrm{m}$ lattice pitch with $2.25 \mu \mathrm{m}$ air-hole diameter. Furthermore, every $1{ }^{\circ} \mathrm{C}$ temperature increment, the proposed ADCPCF exhibits approximately 16\% increases of sensitivity than the existing result. In addition, the proposed ADCPCF reveals that the guiding properties like coupling length, birefringence, and transmission spectra are wavelength and temperature reliance. (C) 2018 Journal of Biomedical Photonics \& Engineering.
\end{abstract}

Keywords: Asymmetric dual circular core photonic crystal fiber (ADCPCF); Birefringence; Chloroform; Sensitivity; Temperature Sensor.

Paper \#3294 received 11 Jun 2018; revised manuscript received 11 Sep 2018; accepted for publication 14 Sep 2018; published online 30 Sep 2018. doi: 10.18287/JBPE18.04.030302.

\section{References}

1. N. Ayyanar, R. V. J. Raja, D. Vigneswaran, B. Lakshmi, M. Sumathi, and K. Porsezian, "Highly efficient compact temperature sensor using liquid infiltrated asymmetric dual elliptical core photonic crystal fiber," Optical Materials 64, 574-582 (2017).

2. J. C. Knight, "Photonic crystal fibres," Nature 424(6950), 847-851 (2003).

3. J. Broeng, D. Mogilevstev, S. E. Barkou, and A. Bjarklev, "Photonic crystal fibers: A new class of optical waveguides," Optical Fiber Technology 5(3), 305-330 (1999).

4. B. J. Eggleton, C. Kerbage, P. Westbrook, R. S. Windeler, and A. Hale, "Microstructured optical fiber devices," Optics Express 9(13), 698-713 (2001).

5. B. Shuai, L. Xia, Y. Zhang, and D. Liu, "A multi-core holey fiber based plasmonic sensor with large detection range and high linearity," Optics Express 20(6), 5974-5986 (2012).

6. T. T. Alkeskjold, J. Lægsgaard, A. Bjarklev, D. S. Hermann, J. Broeng, J. Li, and S.-T. Wu, "All-optical modulation in dye-doped nematic liquid crystal photonic bandgap fibers," Optics Express 12(24), 5857-5871 (2004). 
7. Y. Lu, M. Wang, C. Hao, Z. Zhao, and J. Yao, “Temperature sensing using photonic crystal fiber filled with silver nanowires and liquid," IEEE Photonics Journal 6(3), 1-7 (2014).

8. Z. Liu, C. Wu, M.-L. V. Tse, C. Lu, and H.-Y. Tam, "Ultrahigh birefringence index-guiding photonic crystal fiber and its application for pressure and temperature discrimination," Optics Letters 38(9), 1385-1387 (2013).

9. H. Y. Choi, G. Mudhana, K. S. Park, U.-C. Paek, and B. H. Lee, "Cross-talk free and ultra-compact fiber optic sensor for simultaneous measurement of temperature and refractive index," Optics Express 18(1), 141-149 (2010).

10. J. Xie, B. Xu, Y. Li, J. Kang, C. Shen, J. Wang, Y. Jin, H. Liu, K. Ni, X. Dong, C. Zhao, and S. Jin, "Highsensitivity temperature sensor based on a droplet-like fiber circle," Applied Optics 53(18), 4085-4088 (2014).

11. Y. Yu, X. Li, X. Hong, Y. Deng, K. Song, Y. Geng, H. Wei, and W. Tong, "Some features of the photonic crystal fiber temperature sensor with liquid ethanol filling," Optics Express 18(15), 15383-15388 (2010).

12. J.-M. Hsu, C.-L. Lee, P.-J. Huang, C.-H. Hung, and P.-Y. Tai, "Temperature sensor with enhanced sensitivity based on photonic crystal fiber interferometer with material overlay," IEEE Photonics Technology Letters 24(19), 1761-1764 (2012).

13. S.-J. Qiu, Y. Chen, F. Xu, and Y.-Q. Lu, “Temperature sensor based on an isopropanol sealed photonic crystal fiber in-line interferometer with enhanced refractive index sensitivity," Optics Letters 37(5), 863-865 (2012).

14. X. Yang, Y. Lu, B. Liu, and J. Yao, "Temperature sensor based on photonic crystal fiber filled with liquid and silver nanowires," IEEE Photonics Journal 8(3), 1-9 (2016).

15. W. Qian, C.-L. Zhao, S. He, X. Dong, S. Zhang, Z. Zhang, S. Jin, J. Guo, and H. Wei, "High-sensitivity temperature sensor based on an alcohol-filled photonic crystal fiber loop mirror," Optics Letters, 36(9), 15481550 (2011).

16. Q. Liu, S. Li, H. Chen, Z. Fan, and J. Li, "Photonic crystal fiber temperature sensor based on coupling between liquid-core mode and defect mode," IEEE Photonics Journal 7(2), 1-9 (2015).

17. W. Lin, B. Song, Y. Miao, H. Zhang, D. Yan, B. Liu, and Y. Liu, "Liquid-filled photonic-crystalfiber-based multimodal interferometer for simultaneous measurement of temperature and force," Applied Optics, 54(6), 1309-1313 (2015).

18. K. Naeem, B. H. Kim, B. Kim, and Y. Chung, "High-sensitivity temperature sensor based on a selectivelypolymer-filled two-core photonic crystal fiber in-line interferometer," IEEE Sensors Journal 15(7), 3998-4003 (2015).

19. Y. Wang, M. Yang, D. Wang, and C. Liao, "Selectively infiltrated photonic crystal fiber with ultrahigh temperature sensitivity," IEEE Photonics Technology Letters 23(20), 1520-1522 (2011).

20. Y. Cui, P. P. Shum, D. J. J. Hu, G. Wang, G. Humbert, and X.-Q. Dinh, "Temperature sensor by using selectively filled photonic crystal fiber sagnac interferometer," IEEE Photonics Journal 4(5), 1801-1808 (2012).

21. S. Kedenburg, T. Gissibl, T. Steinle, A. Steinmann, and H. Giessen, "Towards integration of a liquid-filled fiber capillary for supercontinuum generation in the 1.2-2.4 $\mu \mathrm{m}$ range," Optics Express 23(7), 8281-8289 (2015).

22. K. Nielsen, D. Noordegraaf, T. Sørensen, A. Bjarklev, and T. P. Hansen, "Selective filling of photonic crystal fibres," Journal of Optics A: Pure and Applied Optics 7(8), L13-L20, 2005.

23. C. J. de Matos, C. M. Cordeiro, E. M. Dos Santos, J. S. Ong, A. Bozolan, and C. B. Cruz, "Liquid-core, liquidcladding photonic crystal fibers," Optics Express 15(18), 11207- 11212 (2007).

24. R. V. J. Raja, K. Senthilnathan, K. Porsezian, and K. Nakkeeran, "Efficient pulse compression using tapered photonic crystal fiber at $850 \mathrm{~nm}$," IEEE Journal of Quantum Electronics 46(12), 1795-1803 (2010).

25. Q. Liu, S. Li, H. Chen, J. Li, and Z. Fan, "High-sensitivity plasmonic temperature sensor based on photonic crystal fiber coated with nanoscale gold film," Applied Physics Express 8(4), 046701 (2015).

\section{Introduction}

Photonic crystal fibers (PCF) have been investigated widely for their special structure and unique properties like endless single mode, tailoring zero dispersion, enhanced birefringence, and large effective mode area $[1,2]$. PCF is also called holey fibers (HF) or microstructure optical fibers (MOF), which has huge potential for various uses in the telecommunication data transmission devices. In addition, it has a significant impact on the traditional sensor industry. PCFs have the ability to control the light into the fiber, which was not possible earlier. They have shown extensive concentration recently due to its scope of applications in manipulating the modal properties [3]. Moreover, there are many investigators who show interest in designing highly developed sensors where the air-holes are filled with polymer, oil, gas, liquid, and liquid crystal [4-6]. These PCF based sensors have unique properties, difficulties, and design flexibility. However, it is expected that these difficulties are overcome gradually [7]. Optical temperature sensors have been shown a large amount of curiosity nowadays due to high sensitivity, linearity, and stability. 
A significant attention has been given to develop efficient temperature sensor using PCF with different types of configuration. Liu et al. [8] reported an ultrahigh birefringence index-guiding PCF temperature sensor which showed 11 and $11.2 \mathrm{pm} /{ }^{\circ} \mathrm{C}$ sensitivity on behalf of the fast and slow axis, respectively. Choi et al. proposed hollow core PCF to calculate the temperature and refractive index which illustrated the sensitivity of 8.9 and $14.6 \mathrm{~nm} /{ }^{\circ} \mathrm{C}$ at low and high temperature, correspondingly [9]. In 2014, Xie recommended temperature based droplet fiber which demonstrated the sensitivity of $-3.102 \mathrm{~nm} /{ }^{\circ} \mathrm{C}$ with reasonable cost [10]. Recently, Ayyanar reported asymmetric dual elliptical core photonic crystal fiber (DECPCF) which exhibited the sensitivity of $42.99 \mathrm{~nm} /{ }^{\circ} \mathrm{C}$ [1]. The main theme of this work was to increase the sensitivity at low distance over the wide spectrum window. For this, it is measured in $\mathrm{nm} /{ }^{\circ} \mathrm{C}$. However, the fabrication complexity is increased due to the elliptical shape.

To improve the sensitivity and temperature sensing range of a sensor, unusual materials can be used to PCF fabrication like Telluride, Chalcogenide glasses, and liquid materials [11-15]. Recently, it is observed that liquid core PCFs show a large variation of refractive index depending on temperature [1]. Therefore, the development of liquid core PCFs will increase the temperature sensing ability. It is reported that PCFbased temperature sensor where the coupling is done between liquid core and defect mode has the sensitivity of $1.85 \mathrm{~nm} /{ }^{\circ} \mathrm{C}$ [16]. A liquid filled PCF interferometer showed $-24.757 \mathrm{~nm} /{ }^{\circ} \mathrm{C}$ sensitivity for temperature range 19.5 to $22.5^{\circ} \mathrm{C}$ [17]. Another report presented polymer filled dual-core PCF (DC-PCF) which has given sensitivity of $1.595 \mathrm{~nm} /{ }^{\circ} \mathrm{C}$ for the temperature range of $32-38{ }^{\circ} \mathrm{C}$ [18]. In 2011 Wang proposed an ultrasensitive temperature sensor which demonstrated light coupling involving the fundamental and rod mode and sensitivity is observed $54.3 \mathrm{~nm} /{ }^{\circ} \mathrm{C}$. Nevertheless, the delicate power of the rod mode is eliminated through fusion splicing which increased the fabrication difficulties [19]. However, these types of investigations have small temperature detecting window of $1.4{ }^{\circ} \mathrm{C}$ [16]. PCF based Sagnac interferometer presented temperature identifying window of $17{ }^{\circ} \mathrm{C}$ with low sensitivity of $2.58 \mathrm{~nm} /{ }^{\circ} \mathrm{C}$ [20].

Several research groups have been reported different mechanisms for the temperature sensor to increase the sensitivity with small fiber length. In this report, to increase the sensitivity of asymmetric DCPCF (ADCPCF) sensor, adjust the two circular center core radius and either lattice pitch or air hole diameter is varied. To obtain high sensitive compact temperature sensor, the liquid, which has high-temperature sensitivity is the key requirement for the liquid filled PCF. Among the several liquids, chloroform emerges as a potential candidate for the development of liquid filled PCFs, as their refractive index is highly dependent on temperature. Moreover, chloroform is shown broad transmission window from near-infrared (NIR) to midinfrared (MIR) regime, which can be used to detect the temperature range. In the proposed model, the optical properties like effective refractive index difference, coupling length, and transmission spectra are found by using the finite element method (FEM) through perfectly matched layer (PML).

\section{Materials and Methods}

\subsection{Modeling of ADCPCF}

In the proposed design, the dual-core circular PCF is considered where both the core is filled with chloroform. To examine the performance of temperature sensor, a circular core with asymmetric diameter is used due to increase the effective refractive index difference. As a result, it influences the coupling length and transmission spectrum when compared to symmetrical DCPCF. The transmission studies are carried out numerically for various temperature. In addition, the proposed structure is optimized by adjusting the diameter and pitch of the air-holes. Moreover, the coupling between core modes is demonstrated in the proposed design. The refractive index of chloroform is changed with temperature. Furthermore, a certain temperature range can be detected by measuring the transmission spectra and thus the accurate ambient temperature can be obtained. From the transmission spectrum, the compact temperature sensor is constructed and its sensitivity is determined. The structure parameters of proposed ADCPCF is shown in Table 1. The cross-section of the proposed ADCPCF is shown in Fig. 1. The air-holes distribution in the cladding region is a hexagonal pattern. Furthermore, $5.8 \mu \mathrm{m}$ inter-core separation is chosen. The holes of cladding are filled up with air and the background material of cladding is made up of silica. Moreover, both of the dual-cores and air-holes are circular formed which confirm easier fabrication. However, fabrication of liquid core PCFs is already done by applying capillary forces or pressure and careful filling techniques [21-23].

Table 1 Design parameters of the proposed ADCPCF.

\begin{tabular}{|l|c|}
\hline Pitch & $2.9 \mu \mathrm{m}$ \\
\hline Air hole diameter & $2.26 \mu \mathrm{m}$ \\
\hline Core-1 (radius) & $1.615 \mu \mathrm{m}$ \\
\hline Core-2 (radius) & $1.45 \mu \mathrm{m}$ \\
\hline
\end{tabular}

\subsection{Theoretical Background}

For chloroform, variation of refractive index as a function of wavelength at a temperature of $20^{\circ} \mathrm{C}$ can be given [24],

$$
\begin{aligned}
n_{20}(\lambda)=431364+5632.41 \times \lambda^{-2}-2.0805 \times \\
\times 10^{8} \times \lambda^{-4}+1.2613 \times \lambda^{-6}
\end{aligned}
$$


where $\lambda$ represents wavelength of the propagating light. Using eqs. (1), the refractive index of other temperature can be calculated by

$$
n(\lambda, T)=n_{20}(\lambda)+\Delta T \frac{d n}{d T}
$$

where $n(\lambda, T)$ is the refractive index of chloroform at a particular wavelength $\lambda$ for the desired temperature $T$. $\Delta T$ is the difference between the desired temperature.

Also, at $20{ }^{\circ} \mathrm{C}, \frac{d n}{d T}$ gives the rate of variation of refractive index as a function of temperature and takes the value of $-7.9 \times 10^{-4} \mathrm{~K}^{-1}$ for chloroform [1]. The liquid chloroform has very high non-linearity and the refractive index almost equal to that of silica. The background material of the fiber is fused silica whose dispersion relationship corresponding to temperature can be written by the Sellmeier equation [25]

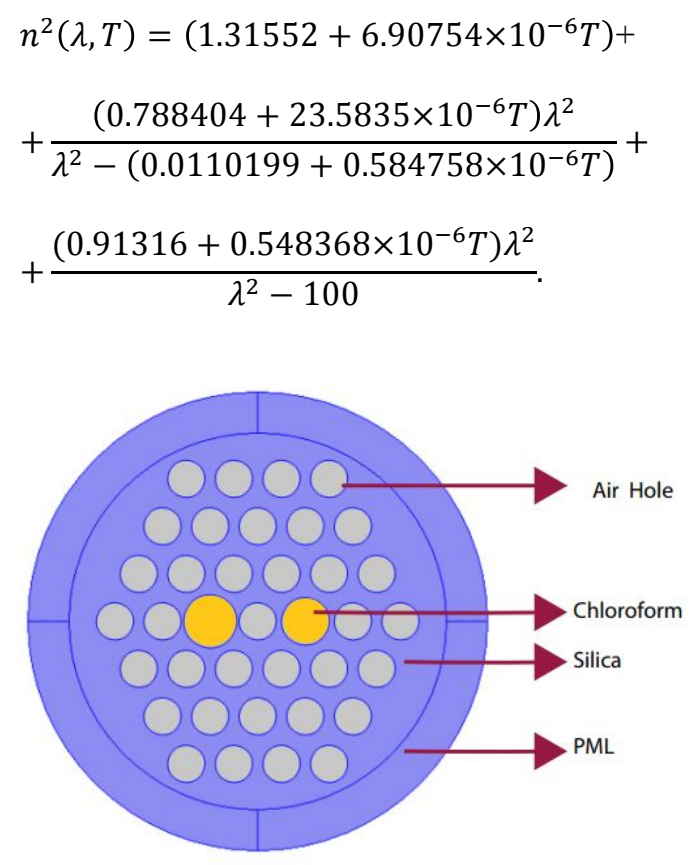

Fig. 1 Cross section of the proposed ADCPCF.

The existing forms of silica are crystalline and amorphous. If the arrangement of silica is ordered, the form is crystalline. In the amorphous form, silica is not in a specific form. Continuous heating and slow cooling is required to form crystalline silica. If the cooling is too fast, molecules of silica cannot rearrange in the role of bonds. Then the form of the silica will be amorphous. The melting temperature of silica is about $167^{\circ} \mathrm{C}$.

The coupling length of $\mathrm{x}$ and $\mathrm{y}$-polarization can be calculated by the formula as follows [1].

$L_{C}=\frac{\lambda}{2\left|n_{\text {even }}-n_{\text {odd }}\right|}$

The coupling modes inside the dual core PCF can be calculated by two even modes and two odd modes, which are also called super modes. The four basic modes $n_{\text {even }}^{x}, n_{\text {even }}^{y}, n_{\text {odd }}^{x}, n_{\text {odd }}^{y}$ are observed in the proposed liquid filled ADCPCF. Their field distribution is shown as Fig. 2. The effective index difference between the super modes of $\mathrm{x}$ and $\mathrm{y}$-polarization can be calculated by

$$
\Delta n_{\text {eo }}=\left|n_{\text {even }}-n_{\text {odd }}\right| \text {, }
$$

which is also called birefringence, $\mathrm{B}=\Delta n_{e o}$. In order to find the temperature of the environment through PCF, the intensity variation of pulse propagation is calculated. According to the mode coupling theory, the optical power transfer from one core to another along the proposed ADCPCF can be calculated by [25]

$\mathrm{P}_{\text {out }}(\lambda)=\mathrm{P}_{\text {in }} \exp \left(\frac{-\alpha \mathrm{L}}{4.343}\right)$,

where $\mathrm{L}$ is the length of the proposed ADCPCF. Thus, calculating the transfer optical power in the second core with a fixed length according to output power equation when the light is injected into core of the proposed PCF. The transmittance can be given by [1]

$\mathrm{T}_{\mathrm{r}}=10 \log _{10}\left(\frac{\mathrm{P}_{\text {out }}}{\mathrm{P}_{\text {in }}}\right)$,

where $\mathrm{P}_{\text {in }}$ is assumed as maximum power of $\mathrm{P}_{\text {out }}$.

The sensitivity of the proposed sensor can be measured through the move of peak wavelength for changing temperature. The sensitivity can be defined as [16]

$S=\frac{\Delta \lambda_{p}}{\Delta T}$

where $\lambda_{p}$ is the peak wavelength.

\section{Results and Discussion}

The coupling length, transmission spectra, and sensitivity of the proposed structure are investigated by the way of calculating the effective refractive index of the coupling modes. The four basic modes $n_{\text {even }}^{x}, n_{\text {even }}^{y}$, $n_{\text {odd }}^{x}, n_{\text {odd }}^{y}$ of the designed liquid filled ADCPCF are computed. The effective index difference between the super modes of $\mathrm{x}$ and $\mathrm{y}$-polarization is calculated by Eq. (5). The variation of effective index difference of super mode with respect to wavelength for $\mathrm{x}$ and $\mathrm{y}-$ polarization from 30 to $35{ }^{\circ} \mathrm{C}$ is shown in Fig. 3. In Fig. 2, the electric field distribution of the proposed ADCPCF is presented. The arrow indicates the direction of electric field of even and odd mode for $\mathrm{x}$ and $\mathrm{y}-$ polarization.

Fig. 3 shows that when the wavelength is increased the effective refractive index difference is decreased for all temperatures. Also, with the increase of the temperature the effective refractive index difference is shown raising. The solid and dashed line indicate the effective index difference of super-modes for $\mathrm{x}$ and $\mathrm{y}$ polarization, accordingly. This index difference is also 
called birefringence which has great impact on polarization maintaining. At $1.55 \mu \mathrm{m}$ wavelength and $30{ }^{\circ} \mathrm{C}$ temperature, the index difference $\Delta n$ is $1.62 \times 10^{-3}$ and $1.63 \times 10^{-3}$ for $x$ and $y$-polarization, respectively. At the same wavelength increasing the temperature from 30 to $35{ }^{\circ} \mathrm{C}$, the index difference is increased to $2.02 \times 10^{-3}$ and $2.03 \times 10^{-3}$ for the similar polarization. Since increasing temperature presents higher index difference it influences the coupling length and transmission spectrum. Moreover, with the increase of every $1{ }^{\circ} \mathrm{C}$ temperature, the effective index difference is increased to almost 4\%. Again, with the reduction of every $100 \mathrm{~nm}$ wavelength the index difference or birefringence is decreased to $0.125 \times 10^{-3}$ and $0.092 \times 10^{-3}$ for 35 and $30{ }^{\circ} \mathrm{C}$ temperature, respectively. Therefore, high temperature shows maximum index difference or birefringence. Moreover, y-polarization demonstrates more birefringence than $x$ due to higher effective refractive index.
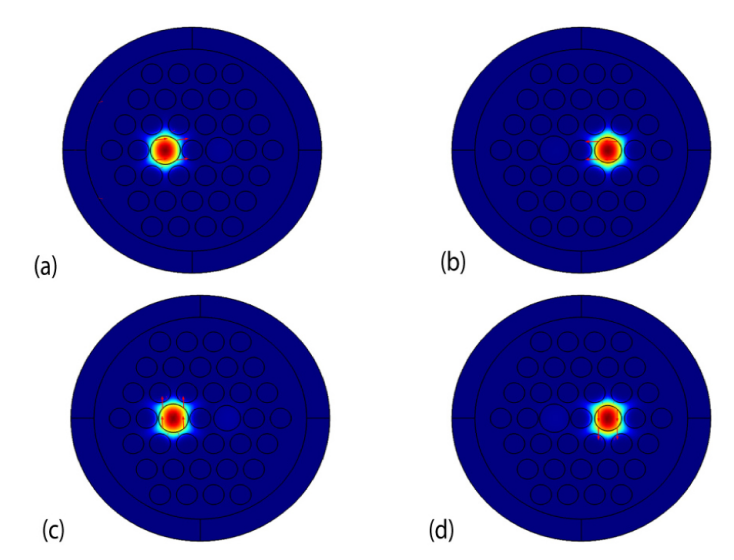

Fig. 2 Electric field distribution of proposed ADCPCF. The arrow indicates the direction of electric field of even and odd mode for $\mathrm{x}$ and $\mathrm{y}$-polarization. (a) and (b) for $\mathrm{x}$, and (c) and (d) for y-polarization.

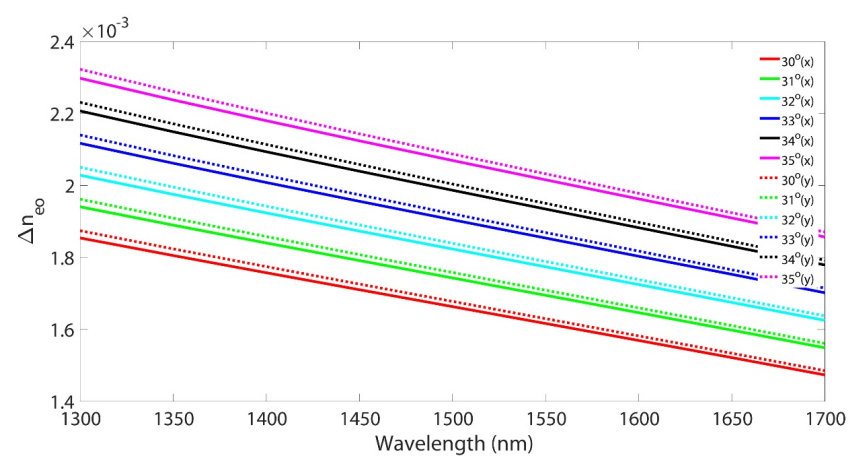

Fig. 3 Effective index difference of $x$ and y-polarization as a function of wavelength for various temperatures. Solid and dashed line present the effective index difference of super-modes for $\mathrm{x}$ and $\mathrm{y}$-polarization, respectively.
Coupling length illustrates the lowest value at which the light is easily transferred from one core to another one. Coupling length of ADCPCF is calculated for temperature range 30 to $35{ }^{\circ} \mathrm{C}$. The temperature dependent coupling length as a function of wavelength for $x$ and y-polarization are plotted in Fig. 4. Coupling length is increased from 0.35 to $0.57 \mathrm{~mm}$ when the wavelength is increased from 1300 to $1700 \mathrm{~nm}$. Moreover, with the increase of the temperature the coupling length is decreased due to increase of the effective index difference as shown in Fig. 3. At $1.3 \mu \mathrm{m}$ wavelength and $x$ polarization, $0.35 \mathrm{~mm}$ coupling length is reduced to $0.28 \mathrm{~mm}$ for increasing the temperature 30 to $35^{\circ} \mathrm{C}$. The rate of this reduction is $4 \%$ for every $1{ }^{\circ} \mathrm{C}$. However, at $1.55 \mu \mathrm{m}$ wavelength the reduction rate is observed $4.3 \%$ for similar consideration. The related inclination is also observed for y-polarization. To propose PCF for temperature sensor, the attenuation of coupling length by temperature introduces an intense PCF sensor. Therefore, it is concluded that coupling length depends on temperature and wavelength. Also, the decrease of coupling length by asymmetric PCF arrangement will be prospective research on a powerful sensor.

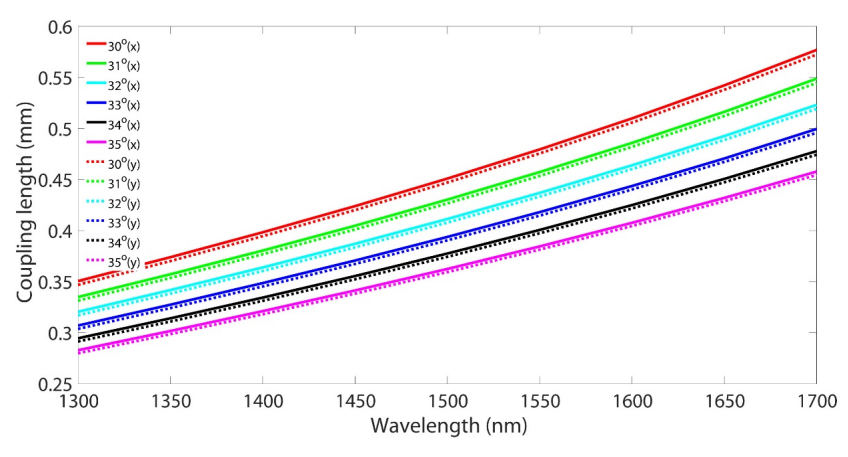

Fig. 4 Coupling length as a function of wavelength for various temperatures with asymmetric design. Solid and dashed line present the coupling length of super-modes for $\mathrm{x}$ and $\mathrm{y}$ polarization, respectively.

The transmission spectrum of the proposed ADCPCF is calculated from Eq. (7). Fiber length is important for calculating the transmission spectrum. Moreover, Longer PCFs have extra affable to temperature sense [11]. Qiang et al. used $1 \mathrm{~mm}$ fiber length [25]. Therefore, the length of the proposed ADCPCF fiber is taken $1.61 \mathrm{~mm}$. It is observed that the dip of the transmittance of this asymmetric structure is increased when the temperature is increased. Also, it is shown that a position of six dip wavelengths for $\mathrm{x}$ polarization at 1399, 1448, 1498, 1547, 1597, and 1646 nm by their consequent temperature from 30 to $35{ }^{\circ} \mathrm{C}$. Therefore, the total wavelength shift is calculated as $249 \mathrm{~nm}$ in ADCPCF as shown in Fig. 5. The numeric analysis represents the dip of the wavelength transfer linearly with temperature from 30 to $35^{\circ} \mathrm{C}$, that is applied for temperature sensing purposes. However, the proposed ADCPCF shows higher wavelength shift comparing to existing report [1]. 


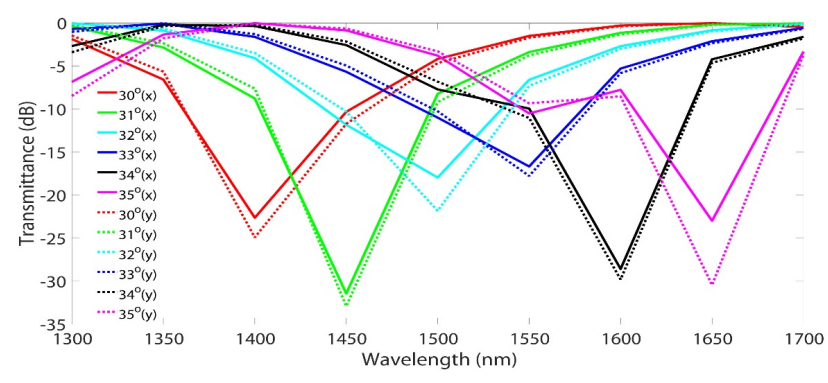

Fig. 5 Calculated transmission of asymmetric design as a function of wavelength for various temperatures. Solid and dashed line present the transmission spectrum of super-modes for $\mathrm{x}$ and $\mathrm{y}$-polarization, respectively.

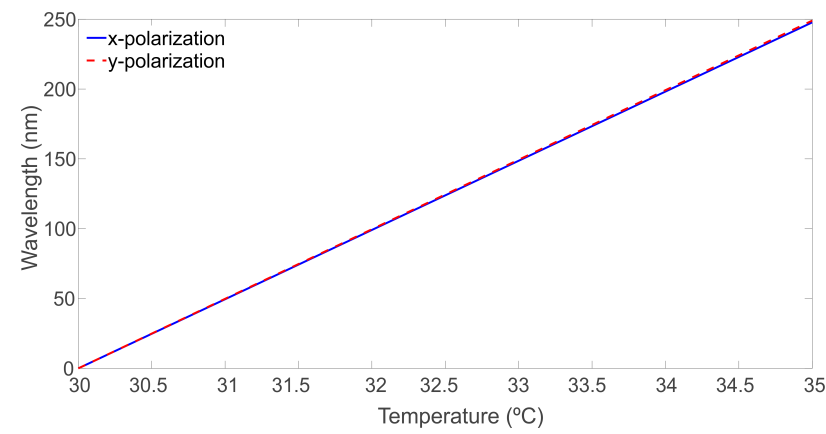

Fig. 6 Wavelength shift of the transmission spectrum for proposed ADCPCF. Temperature range is 30 to $35^{\circ} \mathrm{C}$.

Fig. 6 illustrates the calculated wavelength shift for $\mathrm{x}$ and $\mathrm{y}$-polarization from 30 to $35{ }^{\circ} \mathrm{C}$. For $\mathrm{x}$ polarization the wavelength shift is observed $49.5 \mathrm{~nm}$ where y-polarization shifting is measured $49.8 \mathrm{~nm}$. Moreover, Fig. 7 demonstrates the comparison of wavelength shift of the proposed ADCPCF to DECPCF [1]. The temperature range is considered from 30 to $34{ }^{\circ} \mathrm{C}$. Result shows the maximum wavelength shift is found for y-polarization. Moreover, with the increase of temperature the wavelength shift is raised for both the models. Furthermore, the proposed ADCPCF represents wavelength shift $49.8 \mathrm{~nm}$ for $y$-polarization whereas the existing DECPCF shows $42.99 \mathrm{~nm}$. Therefore, for every $1{ }^{\circ} \mathrm{C}$ temperature increment, the proposed ADCPCF represents almost $16 \%$ increasing of wavelength shift compare to DECPCF.

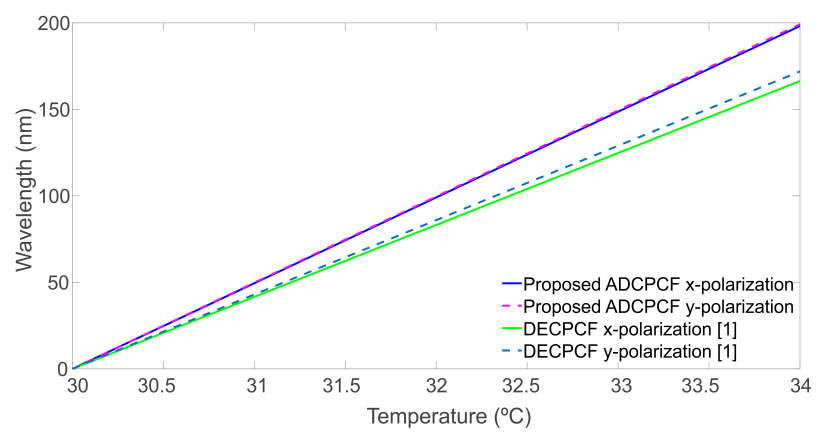

Fig. 7 Wavelength shift of the transmission spectrum for proposed ADCPCF and DECPCF [1]. Temperature range is 30 to $34{ }^{\circ} \mathrm{C}$.
The sensitivity of the proposed sensor can be measured by the transfer of the peak wavelength for the variation of temperature. The computed wavelength transfers of the transmission spectrum for each $1{ }^{\circ} \mathrm{C}$ raising of temperature from $30{ }^{\circ} \mathrm{C}$ in the proposed ADCPCF. To achieve maximum sensitivity with a short distance, optimize the diameter and pitch of the air holes in the cladding. As the air filling factor increases by large air hole diameter and lower pitch value in the cladding, as a consequence tight confinement of light is shown into the core. So, the air-hole diameter is considered from 2 to $2.26 \mu \mathrm{m}$ and pitch value is fixed at $2.9 \mu \mathrm{m}$ as shown in Fig. 8. The general tendency of the figure is that increasing air hole diameter, the sensitivity is raised due to increase of the fill fraction. When air hole diameter is considered to $2 \mu \mathrm{m}$ then sensitivity for $\mathrm{x}$ and y-polarization are observed 41.95 and $42 \mathrm{~nm} /{ }^{\circ} \mathrm{C}$ with $1.61 \mathrm{~mm}$ fiber length. Moreover, the maximum sensitivity for $\mathrm{x}$ and $\mathrm{y}$-polarization are observed 49.55 and $49.80 \mathrm{~nm} /{ }^{\circ} \mathrm{C}$ at the same fiber length when this diameter is considered $2.26 \mu \mathrm{m}$. Therefore, for all cases sensitivity for $\mathrm{x}$ and $\mathrm{y}$-polarization are linearly increased. However, y-polarization has shown more sensitivity than $\mathrm{x}$ due to the effective mode indexes, which are more efficient for y-polarization. Thus, when air-hole diameter is increased, sensitivity for $y$ polarization are more efficient than $\mathrm{x}$-polarization. Moreover, the proposed ADCPCF shows 16\% increase of sensitivity comparing to the exiting result [1].

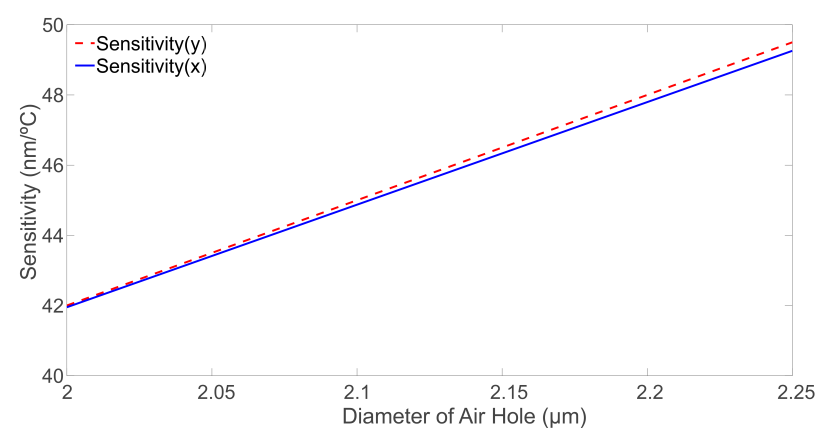

Fig. 8 Sensitivity of the proposed ADCPCF for changing air-hole diameter.

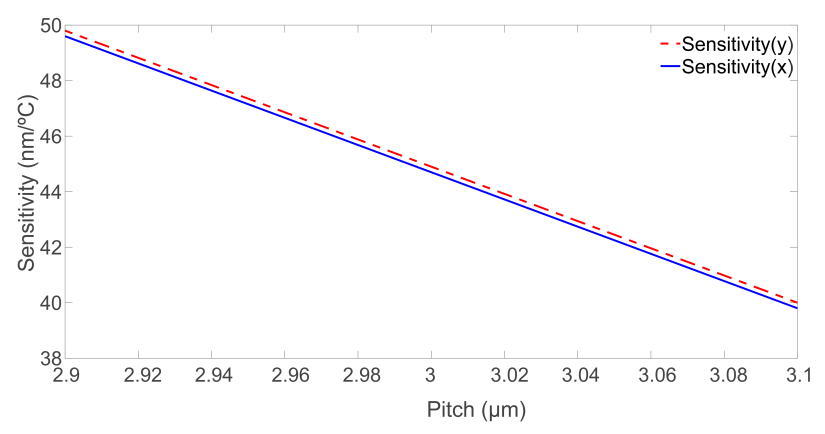

Fig. 9 Sensitivity of the proposed ADCPCF for different pitch values. 
Table 2 Comparison of earlier reported PCF temperature sensors with the proposed chloroform filled ADCPCF.

\begin{tabular}{lccc}
\hline \multicolumn{1}{c}{ PCF materials } & $\begin{array}{c}\text { Length } \\
(\mathbf{c m})\end{array}$ & $\begin{array}{c}\text { Sensitivity } \\
\left(\mathbf{n m} /{ }^{\circ} \mathbf{C}\right)\end{array}$ & Reference \\
\hline $\begin{array}{l}\text { Selectively filled } \\
\text { Polarization PCF } \\
\text { (theoretical and } \\
\text { experimental) }\end{array}$ & 11.7 & 2.58 & {$[20]$} \\
\hline $\begin{array}{l}\text { Alcohol filled PCF } \\
\text { (theoretical and } \\
\text { experimental) }\end{array}$ & 6.1 & 6.6 & {$[15]$} \\
\hline $\begin{array}{l}\text { Liquid and defect } \\
\text { mode PCF } \\
\text { (theoretical) }\end{array}$ & 10 & -1.85 & {$[16]$} \\
\hline $\begin{array}{l}\text { Liquid filled PCF } \\
\text { (theoretical and } \\
\text { experimental }\end{array}$ & 0.7 & -24.75 & {$[17]$} \\
\hline $\begin{array}{l}\text { Polymer PCF } \\
\text { (experimental) }\end{array}$ & 23 & 1.595 & {$[18]$} \\
\hline $\begin{array}{l}\text { Plasmonic PCF } \\
\text { with gold } \\
\text { (theoretical) }\end{array}$ & 0.1 & -2.15 & {$[25]$} \\
\hline $\begin{array}{l}\text { Chloroform } \\
\text { infiltrated DECPCF } \\
\text { (theoretical) }\end{array}$ & 1.41 & 42.99 & {$[1]$} \\
\hline $\begin{array}{l}\text { Chloroform filled } \\
\text { ADCPCF } \\
\text { (proposed) }\end{array}$ & 0.161 & 49.80 & \\
\hline
\end{tabular}

In order to optimize the pitch value, the value is increased from 2.9 to $3.1 \mu \mathrm{m}$ with $0.1 \mu \mathrm{m}$ step size while air-hole diameter is fixed at $2.26 \mu \mathrm{m}$ as shown in Figure. 9. When pitch value is considered to $2.9 \mu \mathrm{m}$ then sensitivity for $\mathrm{x}$ and $\mathrm{y}$-polarization are shown 49.60 and $49.80 \mathrm{~nm} /{ }^{\circ} \mathrm{C}$ with $1.61 \mathrm{~mm}$ fiber length. Increasing the pitch value to $3.1 \mu \mathrm{m}$ then sensitivity of $\mathrm{x}$ and $\mathrm{y}-$ polarization are reduced to 39.80 and $40 \mathrm{~nm} /{ }^{\circ} \mathrm{C}$, respectively. Noted that with the increase of the pitch value, sensitivity is decreased for both $\mathrm{x}$ and $\mathrm{y}$ polarization. This is due to the propagation modes, which are not effective by increasing the air-hoes distance. As a result, light scattering is increased in the fiber. Thus, the proposed PCF structure is a novel compact temperature sensor depend on asymmetric circular core diameter with sensitivity of $49.80 \mathrm{~nm} /{ }^{\circ} \mathrm{C}$ at $1.61 \mathrm{~mm}$, which is much higher than any temperaturebased asymmetric ADCPCF sensor. In Table 2, the comparison is shown of different temperature sensor based on PCF to the proposed ADCPCF model. Nevertheless, the negative sensitivity value demonstrates the symmetric arrangement of PCFs.

\section{Conclusion}

In this report, a high sensitive compact temperature sensor using liquid filled PCF is proposed. Chloroform, which is a temperature-sensitive liquid is inserted into the dual circular core of the proposed ADCPCF. Typically, the asymmetric procedure is illustrated by suitably changing the radius in one of the cores of ADCPCF to enhance the sensitivity. The thermo-optic coefficient of chloroform and silica is utilized to calculate the temperature sensitivity. Moreover, the sensitivity of temperature in the proposed ADCPCF is analyzed through calculation of coupling length and transmission spectrum. In addition, the highest sensitivity is achieved by optimizing the diameter and lattice pitch of the air-holes. The proposed novel temperature sensor based on asymmetric circular diameter shows the high sensitivity of $49.80 \mathrm{~nm} /{ }^{\circ} \mathrm{C}$ at $1.61 \mathrm{~mm}$ fiber length. This is the highest sensitivity using ADCPCF based temperature sensor. Furthermore, the proposed temperature sensor illustrates the guiding properties is temperature and wavelength dependence. The most important benefit of the proposed PCF based temperature sensor is simple to fabricate by applying the current fabrication procedures.

\section{Disclosures}

All authors declare that there is no conflict of interests in this paper. 